\title{
Changes of PTSD Symptoms and School Reconstruction: A Two-year Prospective Study of Children and Adolescents after the Taiwan 921 Earthquake
}

\author{
S.-H. CHEN ${ }^{\star}$ and Y.-C. WU \\ Department of Psychology, National Taiwan University, 1, Sec. 4, Roosevelt Road, Taipei, 106 \\ Taiwan, $R O C$
}

\begin{abstract}
Children and adolescents living in earthquake impacted areas may present various post-traumatic responses and adjustment along the post-traumatic reconstructive phases. Their surrounding environmental damage and reconstructive conditions may influence their adjustment as well. As part of a prospective and longitudinal research project aims to investigate the range and severity of post-traumatic stress disorder (PTSD) symptoms in children and adolescents residing near the epicenter after the Taiwan 921 Earthquake, this paper reports the changes of PTSD symptoms over a 2-year period. The study also examines the effects of school damage and reconstructive condition on PTSD symptoms. Earthquake Exposure Index for Youths and Child Posttraumatic Stress Disorder Reaction Index were administered to 2,028 and 2,077 youths at the first and second year, respectively, from two heavily impacted townships. Given that location, gender, individual and dwelling trauma exposure dose effect were controlled through a balanced sampling procedure and prior statistical confirmation, post-traumatic phase and school damage condition yield significant main effects. Students from the heavily damaged schools consistently displayed significantly more PTSD symptoms, including re-experiencing/avoidance and numbness/maladaptive symptoms, than their counterparts at the first and second year. Decline of prevalence of PTSD symptoms was noted from the first year to the second. Accordingly, there may be a need to implement a broad disaster recovery project with periodic screenings as well as school-specific and schoolbased mental health program.
\end{abstract}

Key words: PTSD symptoms, school reconstruction, Taiwan 921 Earthquake, post-traumatic phase, children and adolescents

\section{Introduction}

Extant studies of natural disasters have often examined the direct effects onto youths' post-traumatic stress disorder (PTSD) on the basis of exposure dose of the disaster as well as gender and age of the subjects. From

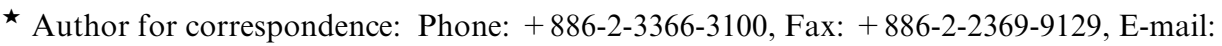
shchen@ntu.edu.tw
} 
a developmental perspective (Pynoos et al., 1996), secondary adversities may be directly and indirectly associated with post-traumatic adjustment. Similar to the notion of secondary adversities, Lindell and Perry (2000) in their protective action decision model suggested that perceived characteristics of a hazard, in terms of the severity, duration of personal consequences such as personal injury, property damage, and disruption of one's work and social life, may predict one's post-hazard adjustment. For children and adolescents, secondary adversities have been frequently reported to be constituted by relocation, resettlement, change in care-taking, and change in family finances as well as medical and rehabilitative treatment for personal injuries and subsequent disabilities. However, much less rigor has been devoted to investigate the psychological impacts of school damage and reconstructive conditions after a collective natural hazard.

It may be reasonable to infer that, because school-age youths spend more hours in school than elsewhere, they may get more affected by the adversities of such a surrounding after a disaster. Collapse or damage in school following an earthquake may present all kinds of trauma reminders on campus. Those ubiquitous trauma reminders constitute an additional source of ongoing distress and pervasive influences on group dynamics, and that in turn bring more ongoing distress (Pynoos et al., 2004). Students from damaged schools may be periodically reminded of renewed traumatic anxiety that often elicits maladaptive reenactment and avoidant behavior.

With a unique, but sad, opportunity brought by a disastrous earthquake described below, our longitudinal and prospective research project aims to investigate plausible associations of earthquake-related features, post-traumatic adjustment, and PTSD in children and adolescents living in the seriously impacted areas along the post-traumatic reconstructive process. The study reported here was part of it and specifically examined the effects of school damage conditions on PTSD symptoms and changes of PTSD symptoms in children and adolescents at the first and second year after the occurrence.

At near midnight of September 21, 1999, the devastating Taiwan 921 Earthquake, which measured 7.3 on the Richter scale, struck the whole island country for almost $1 \mathrm{~min}$, and mainly hit both densely populated farms and the rugged rural mountain regions of Central Taiwan. The Taiwan 921 earthquake was the most deadly natural disaster in Taiwan in the 20th century, leaving a high toll of deaths, injuries, and damage. Approximately 2,494 people lost their lives and over eleven thousand got injured. More than 106,159 houses and a great number of schools were either completely collapsed or damaged. Particularly distressed by the trauma were the children and adolescents living in these regions. Overwhelmed by the fateful events, they experienced personal and/or family injury, 
witnessed death of family and friends, and suffered through damages and collapses of houses. Moreover, they have been experiencing unfortunate adversities and disruption of being 'school-less' due to collapse or severe damage of their schools.

Studies have suggested that more than $10 \%$ of people have been exposed to some types of natural disaster in life (e.g., Norris, 1992; Kessler et al., 1995). The Word Disaster Report 2001 pointed out that earthquake was the world's deadliest natural hazard (IFRC, 2001). Exposure to trauma has been a risk factor in psycho-pathogenic impact noted in human history and literature for years. Although only some cases have experienced devastating consequences, severe traumas may still have both physiological and psychological impacts on most individuals' lives. Especially, PTSD, as one of the most costly consequences, influences not only the individual's life but also the mental health system and society as well.

The extent of trauma exposure appears to be strongly associated with severity and course of post-traumatic stress reactions (e.g., Green, 1991; Lonigan et al., 1994). Also, age and gender may present variable effects on risk for PTSD symptoms (e.g., Shaw et al., 1996; Koral et al., 1999). Likewise, our previous study undertaken one year after the Taiwan 921 earthquake found that, among children and adolescents living in heavily impacted townships, earthquake exposure indexed by self injury, family member(s) injured or killed, and close friends injured or killed were more associated with severity of PTSD. In addition, PTSD severity showed significant main effects for age and gender, and their interaction (Chen et al., 2002a, b).

Common post-traumatic reactions to disaster in western children and adolescents include various kinds of sleep problems, loss of capacity to learn, impaired concentration, intrusive images and thoughts triggered by trauma-related environment; repeating trauma-related play and games, fear of trauma reminders, hypervigilance to dangers, decreased self-efficacy, increased sense of insecurity, loss of derived pleasure from regular activities, anger, irritability, depression, guilt and hopelessness (Orlee, 1993; Lonigan et al., 1994; Shannon et al., 1994).

The profiles of symptom presentation appeared somewhat mixed in Taiwanese youths during short-term period within half a year after the earthquake. For instance, Soong et al. (2000) by using an aboriginal tool, Post-earthquake Questionnaire for Students (PEQS), in a survey conducted three months after the Taiwan 921 Earthquake found that re-experiencing feeling $(48.6 \%)$, avoiding thoughts $(42.5 \%)$, re-living acts $(41.6 \%)$, and fear of being alone $(41.3 \%)$ were most often reported symptoms in 2-9 graders from a town near the epicenter. Chao and $\mathrm{Wu}$ (2000), using the same PEQS, found that, approximately 4 months after the same earthquake, behavioral re-enactment (59.2\%), avoidance of 
thoughts/feelings (54.9\%), and separation anxiety (53.9\%) led the PTSD symptom list in 3-6 graders from another town. Different from the symptom manifestations in younger children, Hsu (2000), by giving the Posttraumatic Stress Reaction Index (PTSRI; Chen et al., 2000) to 681 seniorhigh school students living near the epicenter three to four months after the earthquake found that difficulty concentrating (52.8\%), hypervigilance and oversensitivity to surroundings $(37.7 \%)$, preoccupation with earthquake re-occurrence $(31.7 \%)$, and hypersomnia (34.1\%) were the most often reported symptoms.

With regard to symptom manifestation of a longer period after the earthquake our previous study undertaken on children and adolescents from seriously impacted townships one year after the earthquake found that the most frequent re-experiencing/avoidance symptoms reported were hypervigilance $(55.2 \%$ for males vs. $55.1 \%$ for females and $45.3 \%$ for males vs. $55.8 \%$ for females, for children and for adolescents, respectively), worry misfortune may reoccur $(31.6 \%$ vs. $34.5 \%$ and $21.6 \%$ vs. $30.1 \%$ ), and psychological distress cued by related situations (26.4\% vs. $31.8 \%$ and $19.7 \%$ vs. $29.8 \%$ ). On the whole, younger children presented more PTSD symptoms (Chen et al., 2002a, b).

Moreover, with regard to gender and age interaction effect of symptom manifestations, elementary school boys reported more numbness/ maladaptive symptoms than girls, while male adolescents presented fewer symptoms than their female counterparts. Within the numbness/maladaptive symptom cluster, sleep problems $(21.8 \%$ and $18.8 \%$, for male and female, respectively), memory impairment $(21.2 \%$ and $16.8 \%)$, restricted negative affects $(21.2 \%$ and $16.6 \%)$, and difficulty concentrating $(19.7 \%$ and $17.6 \%)$ were most frequent in elementary school children. Difficulty concentrating $(18.6 \%$ and $19.3 \%$, for male and for female, respectively), memory impairment $(17.2 \%$ and $13.0 \%)$, sleep problems $(12.4 \%$ and $14.8 \%)$, and restricted negative effects $(14.5 \%$ and $10.6 \%$ ) took the lead in the list of junior high school adolescents (Chen et al., 2002a, b).

These existing studies of Taiwanese youths were all conducted within the first year after the earthquake and used various measures. Unanswered is the question whether or not the symptom manifestations in children and adolescents remain over a long period of time. Orlee (1993) pointed out that studies prior to 1985 considered disasters to have only short-term effects on children and few empirical studies on trauma-related psychological problems had been conducted with younger subjects. Only since 1987 more studies about reactions of children and adolescents following trauma have been carried out with mixed findings, as noted in Taiwanese samples. Regardless, it has been documented that, like adult victims, children and adolescents may experience the full range of post-traumatic stress symp- 
toms (e.g., Pynoos et al., 1993; La Greca et al., 1996). Moreover, once the diagnosis is established in childhood and adolescence, PTSD is usually chronic and debilitating (e.g., Nader et al., 1990; Green et al., 1994). Thus, systematic research on children's and adolescents' post-traumatic responses along the post-traumatic reconstructive process can not only render theoretical significance but also useful clinical implication. Such a motif was endeavored into a prospective and longitudinal research project to examine long-term effects of the earthquake and changes of PTSD symptoms over the first 2-year period in children and adolescents living near the earthquake epicenter after the occurrence.

\subsection{AIMS OF THE STUDY}

Lacking previous research on chronic post-disaster psychological reactions of youths in Taiwan constitutes a prime motive for the current research project that focuses mainly on a large-scale investigation with prospective and longitudinal design so as to plausibly give a database for better understanding of psychological sequelae following the occurrence of natural hazards in Taiwan. Given that school conditions following a natural hazard may constitute a secondary adversity for school-age youths and that may in turn play as predictor of their posttraumatic adjustment, it will be of great importance to explore the psychological impacts of school damage conditions in school-age youths after a collective trauma. Thus, this paper primarily reports the data conducted at the first and second year after the Taiwan 921 earthquake and examines the changes of the range and severity of chronic PTSD symptoms exhibited by children and adolescents residing near the epicenter. In this paper, the authors also examine the effects of school damage conditions and post-traumatic phases on PTSD symptoms in children and adolescents.

\section{Method}

\subsection{SETTINGS}

The tragedy in Tai-Chung County and Nan-Tou County of Central Taiwan represented at least $80 \%$ of the total death, injury, and damage tolls after the Taiwan 921 Earthquake. Tung-Hsih Town of Tai-Chung County and Pu-Li Town of Nan-Tou County, located within the perimeter of the earthquake epicenter, had the highest death, injury, and damage tolls in the whole country. Most survivors from these two towns have been relocated to other cities or placed in temporary residences including prefabricated housing, container homes, or sheet-metal shelters after the earthquake. Almost half of their elementary and junior-high schools were 
collapsed or seriously damaged and only very few schools remained undamaged through the earthquake. Thus, it gave us the opportunity to recruit school damage and reconstructive condition as our primary variable for comparisons and select students from both mildly and severely damaged schools separately from both elementary and junior-high levels and both townships.

When data collection for the first-year study were undertaken during the first two weeks of September 2000, there were still substantial number of survivors living in container homes and most schools were still under reconstruction. When data collection for the second-year study were undertaken during November and December of 2001, the proportion of survivors living in container homes remained close to the statistics of the first year, but both mildly and severely damaged schools reported in this paper were all completely reconstructed.

\subsection{SUBJECTS}

Subjects for the first-year and second-year studies were children and adolescents from 4th through 9th graders residing in two most severely damaged towns near the epicenter. They came from four public elementary and four junior high schools. Of each level of school, two located in Tung-Hsih Town and two in Pu-Li Town. Study schools were selected on the basis of location and degree of damage. Half of the schools, at each level, in each town, collapsed and their students were relocated in temporary container classrooms for a long while before reconstruction were finished, and the other half were mildly damaged and remained unmoved. Students from each school were roughly evenly selected from three grades, indicating that the samples were adequately representative of the student population in these two areas.

Of all subjects in the second-year study, two thirds of students continued from the first year samples. The other one third of the first-year subjects have graduated from their former elementary or junior high schools. Once the unusable subjects were eliminated, 2,028 and 2,077 students were recruited for the first and second year study, respectively. Of 2,028 students in the first-year assessment, $49.3 \%$ of students were from elementary school and 50.7\% from junior high school; and 53.2\% were males and $46.8 \%$ were females. Of 2,077 students in the second-year assessment, $44.4 \%$ and $55.6 \%$ were elementary and junior high students, and 52.9\% were males and $47.1 \%$ were females. With regard to their current dwelling conditions, the majority of the youths were living in their original home place where their houses were either undamaged or rebuilt $(83.6 \%$ and $82.7 \%$, for the first- and second-year samples, respectively) and in a 
Table I. Subject characteristics of the study conducted at the first and second year

\begin{tabular}{|c|c|c|c|c|c|}
\hline & \multicolumn{2}{|c|}{$\begin{array}{l}1 \text { year post- } \\
\text { earthquake }\end{array}$} & \multicolumn{2}{|c|}{$\begin{array}{l}2 \text { year post- } \\
\text { earthquake }\end{array}$} & \multirow[t]{2}{*}{ Comparison } \\
\hline & $N$ & $\%$ & $N$ & $\%$ & \\
\hline \multicolumn{6}{|l|}{ Sex } \\
\hline Male & 1078 & 53.2 & 1098 & 52.9 & $\chi^{2}=0.04$, n.s. \\
\hline Female & 950 & 46.8 & 979 & 47.1 & \\
\hline Total & 2028 & 100 & 2077 & 100 & \\
\hline \multicolumn{6}{|l|}{ Current dwelling? } \\
\hline Original house (undamaged or rebuilt) & 1541 & 83.6 & 1649 & 82.7 & $\chi^{2}=0.21$, n.s. \\
\hline Relative's or rented house & 214 & 11.6 & 263 & 13.2 & \\
\hline Container house & 89 & 4.8 & 82 & 4.1 & \\
\hline Unknown $^{\mathrm{a}}$ & 155 & 7.7 & 58 & 2.8 & \\
\hline
\end{tabular}

Note. ${ }^{\text {a }}$ Unknown data were eliminated from the examination of $\chi^{2}$ test.

relatively decent rented or relative's houses $(11.6 \%$ and $13.2 \%$, for the first and second year samples, respectively), leaving $4.8 \%$ of the first year samples and $4.1 \%$ of the second-year samples still residing in the container or prefab houses, respectively (see Table I).

With regard to trauma exposure characteristics, overall, there were about $1.1 \%$ and $1 \%$ of students being moderately or severely hurt through the earthquake at the first- and second-year samples, respectively; $12.5 \%$ and $11.2 \%$ being mildly hurt for the first- and second-year samples, respectively. Regarding loss experiences, $5.4 \%$ and $5.1 \%$ of the first- and secondyear samples had lost at least one of their family members, respectively, and $28.4 \%$ and $26.4 \%$ of the first- and second-year samples had close friends being hurt or killed, respectively (see Table II).

\subsection{MEASURES}

\subsubsection{Earthquake Exposure Index for Youths}

The self-report Earthquake Exposure Index for Youths (EEIY) was modified from the Earthquake Exposure Index (Chen et al., 2002a, b). with additional youth-relevant items to assess the extent of exposure to the earthquake. The EEIY asks about physical injury level in self, injury and/or death in family member(s), injury and/or death in friends, degree of house damage; and current dwellings. 
Table II. Trauma exposure characteristics of subjects recruited for the assessment at first and second year after the earthquake

\begin{tabular}{|c|c|c|c|c|c|}
\hline & \multicolumn{2}{|c|}{$\begin{array}{l}1 \text { year post- } \\
\text { earthquake }\end{array}$} & \multicolumn{2}{|c|}{$\begin{array}{l}2 \text { years post- } \\
\text { earthquake }\end{array}$} & \multirow[t]{2}{*}{ Comparison } \\
\hline & $N$ & $\%$ & $N$ & $\%$ & \\
\hline \multicolumn{6}{|l|}{ Self hurt? } \\
\hline No & 1736 & 86.4 & 1809 & 87.8 & \multirow[t]{4}{*}{$\chi^{2}=2.24$, n.s. } \\
\hline Mildly hurt & 251 & 12.5 & 230 & 11.2 & \\
\hline Moderately hurt & 21 & 1.0 & 18 & 0.9 & \\
\hline Severely hurt & 2 & 0.1 & 3 & 0.1 & \\
\hline \multicolumn{6}{|c|}{ Family member $(s)$ killed? } \\
\hline No & 1898 & 94.6 & 1954 & 94.9 & \multirow[t]{2}{*}{$\chi^{2}=0.17$, n.s. } \\
\hline Yes & 108 & 5.4 & 105 & 5.1 & \\
\hline \multicolumn{6}{|c|}{ Close friend $(s)$ hurt or killed? } \\
\hline No & 1393 & 71.6 & 1498 & 73.6 & \multirow[t]{2}{*}{$\chi^{2}=2.06$, n.s } \\
\hline Yes & 552 & 28.4 & 536 & 26.4 & \\
\hline
\end{tabular}

\subsubsection{UCLA PTSD Index for DSM-IV, Revision 1, Adolescent version}

The self-report UCLA PTSD Index for DSM-IV, Revision 1, Adolescent Version (Pynoos et al., 1996), through forward-backward translation procedures, was adapted to evaluate the incidence of past-trauma experiences (i.e., the 13-item Past-Trauma Experience Survey; PTES) and post-traumatic stress symptoms (i.e., the 20-item checklist of PTSD symptoms; CPTSD). Incidence of past trauma experiences was rated as $0-N O$ or 1$Y E S$, including earthquake, traffic accidents, war, fighting, gun-shot, and so on. Frequency of occurrence of symptoms was rated on a 5-point Likert scale ranging from 0-None to 4-Most of the time. As the tool was first used in Taiwan, the authors conducted psychometric examinations of the scale and reported elsewhere (Lin, 2001; Wu et al., 2002). The CPTSD, by principal component factor analysis with obliminal rotation, yields two meaningful factors, i.e., re-experiencing/avoidance symptoms and numbness/ maladaptive symptoms. The internal consistency Cronbach's $\alpha$ were 0.91, 0.88 and 0.82 , for the total scale, factor of re-experiencing/avoidance symptoms, and factor of numbness/maladaptive symptoms, respectively.

\subsection{PROCEDURE}

In the first-year assessment, all data were collected during the first two weeks of September 2000, right before the first anniversary of the Taiwan 
921 Earthquake. Classroom teachers were invited to assist the investigators to administer the measures. With the support of the principals and teachers, and after a passive consent procedure, all measures were given to the students in their usual classrooms. All responses were guaranteed anonymous. In the second-year assessment, all data were collected during November and December of 2001 with similar procedures and at similar settings of the same target schools. Preliminary analyses were first performed to examine the equivalence of such subject characteristics and exposure characteristics of the student samples that have been reported to be predictive for PTSD between two waves of samples. Chi-square analyses were performed on symptom frequencies. Two-way ANOVA were performed to examine the effects of post-traumatic phase and school reconstruction conditions on PTSD symptoms.

\section{Results}

In order to guarantee equivalent and unbiased sampling for further meaningful comparisons on the target variables in this paper, Chi-square analyses were performed on gender and current dwelling condition between the samples of first- and second-year studies and resulted satisfactorily in that the association of time with neither gender nor current dwelling condition were statistically significant as indicated in Table I. Moreover, before examining the effects of school damage conditions and change of PTSD prevalence and severity over time, equivalence of sample distribution in terms of trauma exposure characteristics were checked up between the two waves of data. As shown in Table II, it resulted in no difference. Thus, the two waves of subjects were eligible for further group comparisons on post-traumatic phases and school damage and reconstructive conditions.

\subsection{POST-TRAUMATIC PHASES AND SCHOOL DAMAGE AND RECONSTRUCTIVE CONDITIONS}

The students were assessed around the first and second anniversary of post-traumatic phases. Their school conditions were classified into severely and mildly damage and reconstructive conditions in terms of whether total reconstruction of the whole school was inspected by governmental technical experts. Means and standard deviations for PTSD total and symptom clusters by posttraumatic phases (time) and school damage and reconstructive conditions (damage) as well as the summary of ANOVA results are presented in Table III.

The PTSD total showed significant main effects for post-traumatic phases $(F=195.56, p<0.001)$ and school damage and reconstructive condi- 


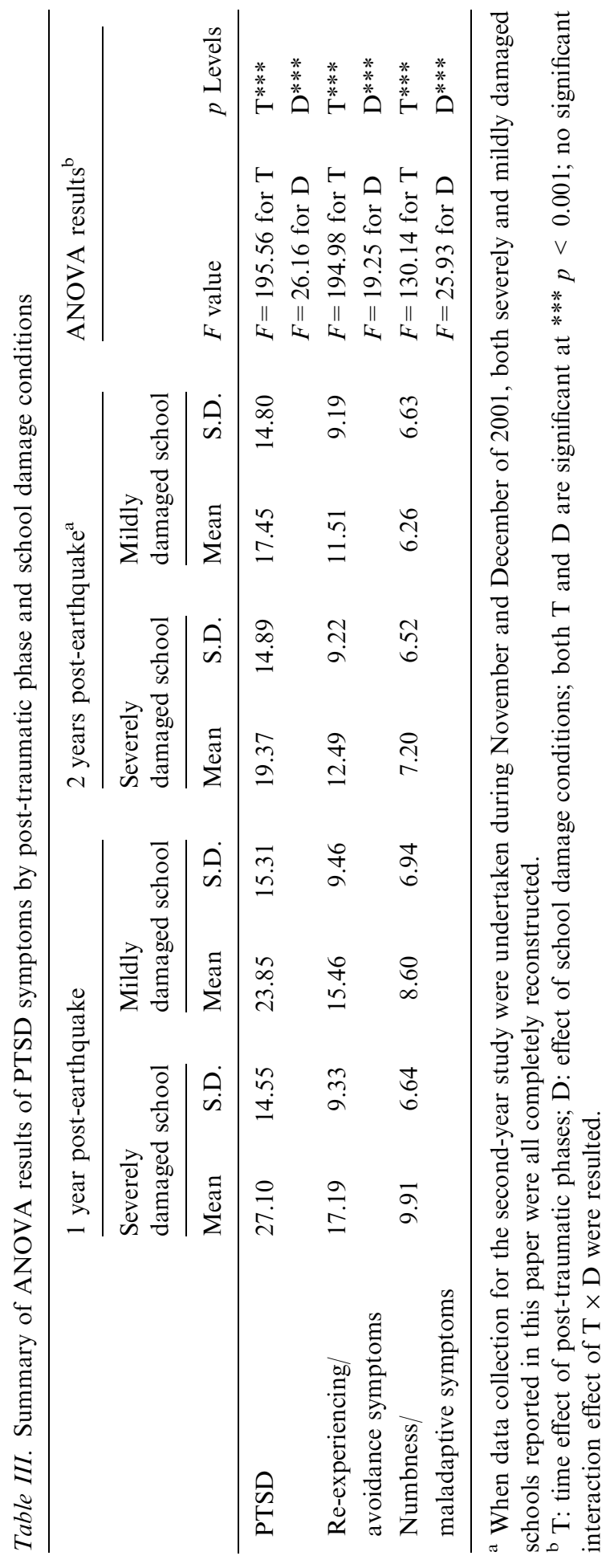


tions $(F=26.16, p<0.001)$, and no significant interaction effect. The reexperiencing/avoidance symptom cluster showed significant main effects for post-traumatic phases $(F=194.98, p<0.001)$ and school damage and reconstructive conditions $(F=19.25, p<0.001)$, and the numbness/maladaptive symptom cluster yielded a significant main effect for post-traumatic phases $(F=130.14, p<0.001)$ and school damage and reconstructive conditions $(F=25.93, p<0.001)$. The data indicated that, as shown in Figure 1, students presented more overall PTSD symptoms, re-experiencing/avoidance symptoms, and numbness/maladaptive symptoms at the first year of post-traumatic phases than the following year. With regard to the effect of school damage and reconstructive condition, students from
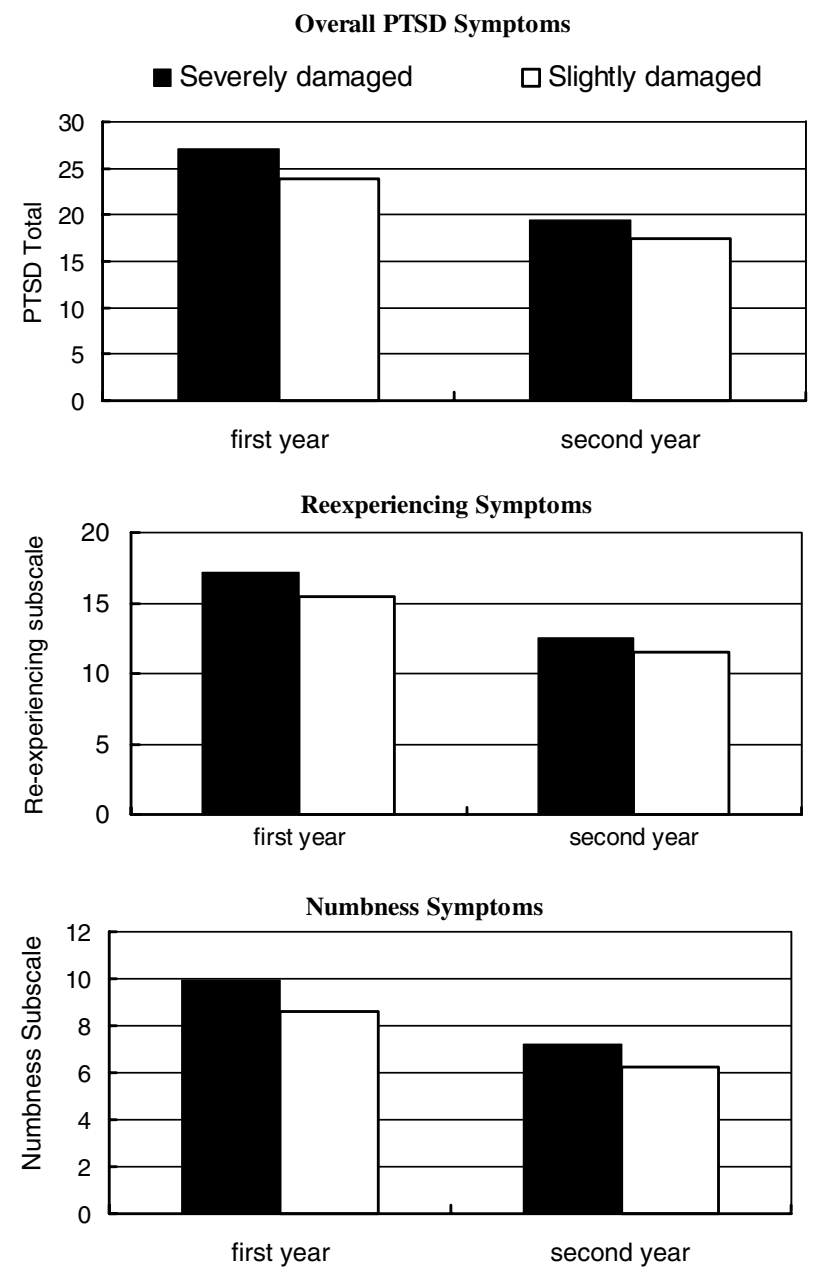

Figure 1. Effects of school damage conditions on PTSD symptoms at the first and second year after the Taiwan 921 Earthquake. 
severely damaged school displayed significantly more overall PTSD symptoms, re-experiencing/avoidance symptoms, and numbness/maladaptive symptoms than their counterparts.

\subsection{CHANGES OF PTSD SYMPTOM PREVALENCE OVER TWO YEARS AFTER THE EARTHQUAKE}

The most frequent re-experiencing/avoidance symptoms reported by students include hypervigilance $(50.9 \%)$, worry misfortune may re-occur $(28.2 \%)$, psychological distress cued by related situations $(25.4 \%)$, intrusive images, sounds, and thoughts $(22.8 \%)$, avoidance of trauma-related thoughts $(22 \%)$, and exaggerated startle responses $(20.1 \%)$. In the numbness/maladaptive symptom cluster, difficulty concentrating $(19.3 \%)$, memory impairment $(16.7 \%)$, sleep problems $(16.7 \%)$, and restricted negative affects $(15.7 \%)$ took the lead in the list at the first year (Table IV).

At the second year post-earthquake, the most frequent re-experiencing/ avoidance symptoms reported by students include hypervigilance $(32.6 \%)$, worry misfortune may reoccur $(18.3 \%)$, psychological distress cued by related situations $(16.4 \%)$, avoidance of trauma-related thoughts $(15.1 \%)$, irritability and anger responses (14.8\%), and intrusive images, sounds, and thoughts $(14.2 \%)$. In the numbness/maladaptive symptom cluster, difficulty concentrating (13.7\%), sleep problems $(13.6 \%)$, memory impairment $(12.5 \%)$, and restricted negative effects $(11.3 \%)$ took the lead at the second year.

Overall, change of PTSD symptoms in students at various post-traumatic phases was noted in all re-experiencing/avoidance and numbness/maladaptive symptoms. From the first to the second year after the earthquake, the prevalence of all PTSD symptoms indicated by UCLA PTSD Index for DSM-IV decreases at significant levels of $p s<0.01 \sim 0.001$ as shown in Table IV.

\subsection{COMPARISONS OF SCHOOL DAMAGE CONDITIONS AND PTSD SYMPTOM PREVALENCE}

For students from severely damaged schools, as shown in Table V, the most frequent re-experiencing/avoidance symptoms reported include hypervigilance $(43.1 \%)$, worry misfortune may reoccur $(24.3 \%)$, psychological distress cued by related situations (23\%), and intrusive images, sounds, and thoughts $(20.7 \%)$. In the numbness/maladaptive symptom cluster, difficulty concentrating (18\%), memory impairment $(16.3 \%)$, and sleep problems $(15.6 \%)$ took the lead in the list.

For students from mildly damaged schools, the most frequent re-experiencing/avoidance symptoms reported include hypervigilance $(40.6 \%)$, 
Table IV. Comparison of prevalence of PTSD symptoms displayed at the first and second year

\begin{tabular}{|c|c|c|c|c|c|}
\hline & \multicolumn{2}{|c|}{$\begin{array}{l}1 \text { year } \\
\text { post- } \\
\text { earth- } \\
\text { quake }\end{array}$} & \multicolumn{2}{|c|}{$\begin{array}{l}2 \text { years } \\
\text { post- } \\
\text { earth- } \\
\text { quake }\end{array}$} & \multirow[t]{2}{*}{ Comparison } \\
\hline & $N$ & $\%$ & $N$ & $\%$ & \\
\hline \multicolumn{6}{|l|}{ Reexperiencing/avoidance symptoms } \\
\hline Hypervigilance (S1) & 993 & 50.9 & 647 & 32.6 & $\chi^{2}=135.95^{* * *}$ \\
\hline Worry misfortune may reoccur (S20) & 549 & 28.2 & 359 & 18.3 & $\chi^{2}=53.48 * * *$ \\
\hline Cues/psychological distress (S2) & 495 & 25.4 & 325 & 16.4 & $\chi^{2}=47.88 * * *$ \\
\hline Avoidance of trauma-related thoughts (S9) & 426 & 22.0 & 297 & 15.1 & $\chi^{2}=30.416^{* * *}$ \\
\hline Intrusive images, sounds and thoughts (S3) & 439 & 22.8 & 278 & 14.2 & $\chi^{2}=47.73 * * *$ \\
\hline Exaggerated startle responses (S12) & 389 & 20.1 & 246 & 12.5 & $\chi^{2}=40.88 * * *$ \\
\hline Irritability and anger (S4) & 377 & 19.4 & 292 & 14.8 & $\chi^{2}=14.81 * * *$ \\
\hline Avoiding activities, places and people (S17) & 354 & 18.3 & 239 & 12.2 & $\chi^{2}=28.65^{* * *}$ \\
\hline Cues/pysiological reactions (S18) & 291 & 15.0 & 169 & 8.6 & $\chi^{2}=38.06^{* * *}$ \\
\hline Sense of reliving the experiences (S6) & 345 & 17.8 & 193 & 9.8 & $\chi^{2}=53.66 * * *$ \\
\hline Recurrent distressing dreams (S5) & 296 & 15.4 & 197 & 10.1 & $\chi^{2}=23.98^{* * *}$ \\
\hline \multicolumn{6}{|l|}{ Numbness/maladaptive symptoms } \\
\hline Difficulty concentrating (S16) & 374 & 19.3 & 269 & 13.7 & $\chi^{2}=22.50 * * *$ \\
\hline Memory impairment (S15) & 321 & 16.7 & 245 & 12.5 & $\chi^{2}=13.37 * * *$ \\
\hline Insomnia and difficulty falling asleep (S13) & 324 & 16.7 & 269 & 13.6 & $\chi^{2}=7.09 * *$ \\
\hline Restricted negative effect (S11) & 303 & 15.7 & 223 & 11.3 & $\chi^{2}=15.921 * * *$ \\
\hline Guilty feeling (S14) & 260 & 13.4 & 145 & 7.4 & $\chi^{2}=38.38 * * *$ \\
\hline Restricted positive effect (S10) & 243 & 12.6 & 142 & 7.3 & $\chi^{2}=30.39 * * *$ \\
\hline Sense of foreshortened future (S19) & 232 & 11.9 & 176 & 9.0 & $\chi^{2}=9.24 * *$ \\
\hline Detachment from others (S8) & 160 & 8.3 & 113 & 5.7 & $\chi^{2}=9.55^{* *}$ \\
\hline Diminished interest in significant activities (S7) & 160 & 8.2 & 106 & 5.4 & $\chi^{2}=12.63 * * *$ \\
\hline
\end{tabular}

$* * p<0.01, * * * p<0.001$.

worry misfortune may reoccur $(22.4 \%)$, and psychological distress cued by related situations (19.1\%). In the numbness/maladaptive symptom cluster, difficulty concentrating $(15.2 \%)$, sleep problems $(14.8 \%)$, and memory impairment $(13.2 \%)$, took the lead in the list.

Overall, comparisons of PTSD symptom prevalence on school damage conditions yield that significantly higher prevalence of intrusive images and thoughts, voidance behaviors, psychological and physiological distress, irritability and anger of re-experiencing/avoidance symptom cluster as well as memory impairment, difficulty in concentrating, and restricted affects of 
Table V. Comparison of prevalence of PTSD symptoms between severely and mildly damaged schools at the first year post the earthquake

\begin{tabular}{|c|c|c|c|c|c|}
\hline & \multicolumn{2}{|c|}{$\begin{array}{l}\text { Severely } \\
\text { damaged } \\
\text { school }\end{array}$} & \multicolumn{2}{|c|}{$\begin{array}{l}\text { Mildly } \\
\text { damaged } \\
\text { school }\end{array}$} & \multirow[t]{2}{*}{ Comparison } \\
\hline & $N$ & $\%$ & $N$ & $\%$ & \\
\hline \multicolumn{6}{|l|}{ Reexperiencing/avoidance symptoms } \\
\hline Hypervigilance (S1) & 756 & 43.1 & 884 & 40.6 & $\chi^{2}=2.47$ \\
\hline Worry misfortune may reoccur (S20) & 423 & 24.3 & 485 & 22.4 & $\chi^{2}=1.98$ \\
\hline Cues/psychological distress (S2) & 403 & 23.0 & 417 & 19.1 & $\chi^{2}=8.74 * *$ \\
\hline Avoidance of trauma-related thoughts (S9) & 343 & 19.8 & 380 & 17.6 & $\chi^{2}=3.15$ \\
\hline Intrusive images, sounds and thoughts (S3) & 359 & 20.7 & 358 & 16.6 & $\chi^{2}=10.98^{* *}$ \\
\hline Exaggerated startle responses (S12) & 314 & 18.2 & 321 & 14.8 & $\chi^{2}=7.78 * *$ \\
\hline Irritability and anger (S4) & 329 & 18.8 & 340 & 15.7 & $\chi^{2}=6.68 *$ \\
\hline Avoiding activities, places and people (S17) & 299 & 17.2 & 294 & 13.6 & $\chi^{2}=9.32 * *$ \\
\hline Cues/physiological reactions (S18) & 228 & 13.1 & 232 & 10.8 & $\chi^{2}=5.23^{*}$ \\
\hline Sense of reliving the experiences (S6) & 244 & 14.0 & 294 & 13.6 & $\chi^{2}=0.17$ \\
\hline Recurrent distressing dreams (S5) & 236 & 13.7 & 257 & 12.0 & $\chi^{2}=2.38$ \\
\hline \multicolumn{6}{|l|}{ Numbness/maladaptive symptoms } \\
\hline Difficulty concentrating (S16) & 313 & 18.0 & 330 & 15.2 & $\chi^{2}=5.50^{*}$ \\
\hline Memory impairment (S15) & 282 & 16.3 & 284 & 13.2 & $\chi^{2}=7.37 * *$ \\
\hline Insomnia and difficulty falling asleep (S13) & 273 & 15.6 & 320 & 14.8 & $\chi^{2}=0.55$ \\
\hline Restricted negative effect (S11) & 260 & 14.9 & 266 & 12.3 & $\chi^{2}=5.81^{*}$ \\
\hline Guilty feeling (S14) & 186 & 10.7 & 219 & 10.1 & $\chi^{2}=0.37$ \\
\hline Restricted positive effect (S10) & 185 & 10.7 & 200 & 9.3 & $\chi^{2}=2.01$ \\
\hline Sense of foreshortened future (S19) & 190 & 10.9 & 218 & 10.1 & $\chi^{2}=0.66$ \\
\hline Detachment from others (S8) & 129 & 7.4 & 144 & 6.6 & $\chi^{2}=0.92$ \\
\hline Diminished interest in significant activities (S7) & 128 & 7.3 & 138 & 6.3 & $\chi^{2}=1.53$ \\
\hline
\end{tabular}

${ }^{*} p<0.05,{ }^{* *} p<0.01$.

numbness/maladaptive symptom cluster were noted in students from severely damaged schools $(p s<0.05 \sim 0.01)$.

\section{Discussion}

By using more representative youth samples from two harshly impacted townships and assessing the subjects periodically after the Taiwan 921 Earthquake, this paper mainly reports that: (1) in addition to other frequently-studied exposure characteristics such as self injury and loss of family or close friends, adverse school damage conditions had direct effect 
on the severity of PTSD symptoms in youths, and (2) remarkable decline of all PTSD symptoms in youths were noted from the first to the second year after the occurrence. It is also worthy to note that there were still an undeniable number of earthquake-exposed children and adolescents continuously residing in container or prefab houses at one and two years after the earthquake.

\subsection{CHRONICITY OF PTSD SYMPTOMS IN YOUTHS AFTER THE TAIWAN 921 EARTHQUAKE}

The overall adjustment in students has moved toward positive direction as time went by. However, the proportion of students who kept on experiencing reexperiencing/avoidance symptoms two years after the Earthquake was not less than expected. Especially, anxiety-prone symptoms such as hypervigilance and worry misfortune may re-occur were displayed in no less than one third and about one fifth of the subjects, respectively. The present study resulted in similar chronic symptom patterns found by Bradbaun (1991) and Green et al. (1991). Bradburn (1991) found that recollection of the earthquake caused by reminders, feeling fearful while recollecting the event, exaggerated startle responses, and intrusive thoughts were most frequent in children of 10-12 years old six to eight months after the San Francisco Earthquake. Green et al. (1991) found that the most frequently reported symptoms in children two years after the Buffalo Creek flooding disaster included painful feelings caused by reminders, diminished social activities, and restricted effects.

Albeit that this paper did not intend to define full-blown PTSD diagnosis closely resembling the DSM-IV diagnostic criteria for youths, the aforementioned symptoms appear to be more trauma-specific and may lead to future PTSD diagnosis, if sustained. Herman (1992) has speculated that, according to the hypothetical conception of developmental arrest, any traumatization during childhood or adolescence may transform into psychological disorders like conduct disorder, depression, and psychosomatic symptoms and may lead to certain complications later on in life. Differently, it has been postulated that the relationship of developmental level with the extent of PTSD symptoms following a trauma may not be as simple and straightforward as it appears (Maercker, 1999). More specifically, it was assumed that childhood traumatization would lead to hysterical movement disorders, anxiety attacks, and antisocial behavior in later life and traumatization during adolescence may lead to psychosomatic illnesses (Bensheim, 1960, cited by Maercker, 1999). Before this speculation can be examined perhaps 10 years later, it will be essential to inspect the specific effects of developmental stage and related variables on post-traumatic responses in the earthquake-affected children and adolescents. Indeed, the 
present paper, reporting part of the data from a longitudinal series of prospective research, hopes to provide a database for a more in-depth understanding of the link between childhood trauma and future psychopathology.

\subsection{SCHOOL RECONSTRUCTION: AN IMPERATIVE ROLE FOR POST-TRAUMATIC ADJUSTMENT IN YOUTHS}

It is noteworthy that the transition from late childhood to early adolescence is assumed to be a period of refinement of concepts about self and world as well as changes in interpersonal relationships (Erikson, 1968). Traumatization at these stages is often considered to cause a breaching of emotional consolidation in developmental drift (e.g., Pynoos et al., 1996; Maercker, 1999). According to the survey by Csikszentmihalyi and Larson (1984), adolescents spent about one-third of their awakening time at school, taking the lead to elsewhere including their own home. It is thus reasonable to infer that school is the prime place and resource for adolescents to grow at usual time and to restore growth at particular time after a collective trauma such as the earthquake. The threat perception of an old environment following a natural hazard may play as a predictor of post-traumatic responses (Perry and Lindell, 1982; Lindell and Perry, 2000).

Like other exposure variables that may be detrimental for post-traumatic adjustment, the school conditions, especially when appearing chaotic due to severe destruction after the earthquake, may hinder students from regaining resource for growth as well as sense of safety of the environment which previously contains them the most. As speculated by Pynoos et al. (2004) that the trauma reminders are ubiquitous and thus pervasively influences on group dynamics, students from more damaged schools may be more likely to be reminded of renewed traumatic anxiety and thus display more maladaptive reenactment and avoidant behavior. Our data supported this as shown in Table V. More specifically, higher prevalence of intrusion, avoidance, psychological and physiological distress, memory impairment, restricted affects, and difficulty concentration were noted in students from severely damaged schools than their counterparts. It is thus of great importance to start school reconstruction at a very early stage right after the earthquake.

The pattern of symptom prevalence found in the second year appears to be much more positive, but yet somewhat consistent with the pattern found in the previous year, suggesting plausible chronicity of hypervigilance, worry, distress and restricted negative effects, intrusion and avoidance, difficulty concentrating and memory impairment, and sleep problems. The disparities of findings from previous studies may reflect methodological differences. 
Comparisons with other local studies are limited by various assessment times elapsed from the earthquake, sample representativeness, and various instruments. The inconsistencies of present findings of Taiwanese youths may arise from the diverse natures and levels of disaster exposure, the age of the children exposed to the disaster, varieties of instruments, various assessment time periods elapsed from disaster occurrence, and ethnocultural differences of samples (McFarlane, 1987; Friedman and Marsella, 1996; March et al., 1997; Koral et al., 1999).

\section{Conclusion}

Findings of the present study are limited in several ways. First, those whose households were more damaged may have already moved to other cities shortly after the earthquake, were not recruited for the first- and second-year sample. Second, while the present findings could be strengthened by a population-based sampling strategy, its ability to generalize suffered because of lacking a non-exposure sample recruited from a non-affected area in the data set. Last and probably very important, individual difference of threat perception of school conditions and predisposition of each youth may play similarly important roles to directly predict PTSD or to interplay with school damage condition and posttraumatic phases to influence the development of PTSD, but yet to be answered in this paper.

Little information exists concerning long-term post-traumatic response patterns nor symptom changes along the post-traumatic reconstructive phases among children and adolescents in Taiwan after the 921 Earthquake. Extant local studies mainly reported short-term post-traumatic symptoms and used rather restricted samples from only one school or one town. Thus, the present paper may merit some attention for its periodic and systematic assessment and using mixed design with both cross-sectional and longitudinal samples as well as a community-based sampling. Finally, as pointed out by Pynoos et al. (1996) and Pynoos et al. (1998), systematic community and population-based studies will allow for more rigorous investigation of factors that predict or mediate the severity and course of post-traumatic reactions among children and adolescents. Further follow-up research, if plausible, should include a non-exposure sample in order to examine the dose effect along a broader spectrum of trauma exposure. More research attention should focus on school conditions interplay between school conditions and healing time, and will contribute to a better understanding of human sufferings/revitalizations, especially in younger victims. Moreover, relatively higher vulnerability of children and adolescents should call more professional attention to early prevention and 
intervention. Given that school damage and reconstructive conditions significantly influence the development and maintenance of PTSD symptoms, it should be a priority for the government and community organizations to start school reconstruction at a very early stage right after the occurrence of a natural hazard.

\section{Acknowledgements}

The data reported in this paper was part of a research project supported by grants from the National Center for Research on Earthquake Engineering, Taipei, Taiwan, R.O.C. [NCREE-00-061] and National Science Council, Taiwan [NSC-90-2625-Z-002-033]. The authors would like to thank all the principals and teachers of the study-recruited elementary and junior high schools in the earthquake epicenter for their substantial assistance with data collection and all the children and adolescents for their participation. We are also grateful to Dr Fu-Chien Hung, Ms Ya-Ping Lee, Ms Yi-Hui Lin, Ms Yi-Wen Kung, Mr Chia-Hwa Lee and Ms Yun-Feng Hou for their assistance in data collection and analyses.

\section{References}

Bradburn, I. S.: 1991, After the earth shook: children's stress symptoms 6-8 months after a disaster, Adv. Behav. Res. Ther. 13, 173-179.

Chao, C. C. and Wu, Y. Y.: 2000, Preliminary report of post-traumatic stress reactions in child survivors after the Taiwan 921 Earthquake, in C. H. Loh and I. W. Liao (eds.), Proceedings of International Workshop on Annual Commemoration of Taiwan 921 Earthquake, Vol. IV-Social Aspect, National Center for Research on Earthquake Engineering, Taipei, pp. 270-282.

Chen, S. H., Hung, F. C., Lin, Y. S., and Tseng, H. M.: 2000, Lessons from the 921 Earthquake: trauma, psychosocial reactions, and psychological growth, In: C. H. Loh and I. W. Liao (eds.), Proceedings of International Workshop on Annual Commemoration of Taiwan 921 Earthquake, Vol. IV-Social Aspect, National Center for Research on Earthquake Engineering, Taipei, pp. 318-331.

Chen, S. H., Hung, F. C., Lin, Y. S., and Tseng, H. M.: 2002a, Trauma and psychosocial aftermath among high- and low-exposure adults three months post the 921 Chi-Chi Earthquake in Taiwan, Chin. J. Psychol. 44(2), 167-188.

Chen, S. H., Lin, Y. H., Tseng, H. M., and Wu, Y. C.: 2002b, Posttraumatic stress reactions in children and adolescents one year after the 1999 Taiwan Chi-Chi Earthquake, J. Chin. Inst. Eng. 25(8), 597-609.

Csikszentmihalyi, M. and Larson, R.: 1984, Being Adolescent: Conflict and Growth in the Teenage Years, Basic Books, New York.

Erikson, E. H.: 1968, Identity, Youth, and Crisis, Norton, New York.

Friedman, M. J. and Marsella, A. J.: 1996, Posttraumatic stress disorder: an overview of the concept. In: A. J. Marsella, M. J. Friedman, E. T. Gerrity and R. M. Scurfield (eds.), Ethnocultural Aspects of Posttraumatic Stress Disorder: Issues, research, and Clinical Applications. American Psychological Association, Washington, DC, pp. 11-32. 
Green, B. L.: 1991, Evaluating the effects of disasters, J. Consult. Clin. Psychol. 59, 538-546.

Green, B. L., Grace, M., Vary, M. G., Kramer, T., Gleser, G. C., and Leonard, A. C.: 1994, Children of disaster in the second decade: a 17 year follow-up of Buffalo Creek survivors, J. Am. Acad. Child Psy. 33(1), 71-79.

Green, B. L., Korol, M., Grace, M. C., Vary, M. G., Leonard, A. C., Gleser, G. C., and Cohen, S. S.: 1991, Children and disaster: age, gender and parental effects on PTSD symptoms, J. Am. Acad. Child Psy. 30(6), 945-951.

Herman, J. L.: 1992, Trauma and Recovery, Basic Books, New York.

Hsu, W. Y.: 2000, Coping styles and psychological symptoms in students from 921 earthquake. In: C. H. Loh and I. W. Liao (eds.), Proceedings of International Workshop on Annual Commemoration of Taiwan 921 Earthquake, Vol. IV - Social Aspect, National Center for Research on Earthquake Engineering, Taipei, pp. 256-269 (in Chinese).

IRFC (International Federation of the Red Cross and the Red Crescent Societies): 2001, World Disaster Report 2001, Martinus Nijhoff, Dordrecht.

Kessler, R. C., Sonnega, A., Bromet, E., Hughes, M., and Nelson, C. B.: 1995, Posttraumatic stress disorder in the national comorbidity survey, Arch. Gen. Psychiat. 52(12), 1048-1060.

Koral, M., Green, B. L., and Gleser, G. C.: 1999, Children's responses to a nuclear waste disaster: PTSD symptoms and outcome prediction, J. Am. Acad. Child Psy. 38(4), 368-375.

La Greca, A. M., Vernberg, E. M., Silverman, W. L., and Prinstein, M. J.: 1996, Symptoms of posttraumatic stress in children after Hurricane Andrew: a prospective study, J. Consult. Clin. Psychol. 64, 712-723.

Lin, Y. H.: 2001, Posttraumatic Stress Reaction of Adolescents after the Taiwan 921 Earthquake: Gender and Exposure Effect Analysis, Unpublished Master Thesis, National Taiwan University, Taipei.

Lindell, M. K. and Perry, R. W.: 2000, Household adjustment to earthquake hazard: a review of research, Environ. Behav. 32(4), 461-501.

Lonigan, C. J., Shannon, M. P., Taylor, C. M., Finch, A. J., and Sallee, F. R.: 1994, Children exposed to disaster, II: risk factors for the development of posttraumatic symptomatology, J. Am. Acad. Child Psy. 33, 94-105.

Maercker, A.: 1999, Lifespan psychological aspects of trauma and PTSD: symptoms and psychosocial impairments, In: A. Maercker, M. Schützwohl and Z. Solomon (eds.), PostTraumatic Stress Disorder: A Lifespan Developmental Perspective, Hogrefe and Huber Publishers, Seattle, pp. 7-41.

March, J. S., Amaya-Jackson, L., Terry, R., and Costanzo, P.: 1997, Posttraumatic symptomatology in children and adolescents after an industrial fire, J. Am. Acad. Child Psy. 36, 1080-1088.

McFarlane, A. C.: 1987, Posttraumatic phenomena in a longitudinal study of children following a natural disaster, J. Am. Acad. Child Psy. 26, 764-749.

Nader, K., Pynoos, R., Fairbanks, L., and Frederick, C.: 1990, Children's PTSD reactions one year after a sniper attack at their school, Am. J. Psychiat. 147(11), 1526-1530.

Norris, F.: 1992, Epidemiology of trauma: frequency and impact of different potentially traumatic events on different demographic groups, J. Consul. Clin. Psychol. 60, 409-418.

Orlee, U.: 1993, Annotation: children's reaction to traumatic event, J. Child Psychol. Psyc. 34(2), 115-127.

Perry, R. W. and Lindell, M. K.: 1982, Threat perception and public response to volcano hazard, J. Soc. Psychol. 116, 199-204.

Pynoos, R. S., Goenjian, A., Karakashian, M., Tashjian, M., and Manjikian, R.: 1993, Posttraumatic stress reactions in children after the 1988 Armenian earthquake, Brit. J. Psychiat. 163, 239-247. 
Pynoos, R. S., Steinberg, A. M., and Geonjian, A.: 1996, Traumatic stress in childhood and adolescence: recent developments and current controversies, In: B. A. van der Kolk, A. C. Mcfarlane and L. Weisaeth (eds.), Traumatic Stress: The Effects of Overwhelming Experience on Mind, Body and Society, NY: The Guilford Press.

Pynoos, R. S., Goenjian, A. K., and Steinberg, A. M.: 1998, A public mental health approach to the post-disaster treatment of children and adolescents, Psychiat. Clin. N. Am. 7, $195-210$

Pynoos, R. S., Steinberg, A. M., Dyb, G., Goenjian, A. K., Chen S. H., and Brymer, M. J.: 2004, Reverberations of danger, trauma, and PTSD on group dynamics, In: B. Skalarow, S. W. Twemlow and S. M. Wilkinson (eds.), Analysts in the Trenches: Streets, Schools, War Zones, The Analytic Press, Hillsdale New Jersey.

Shannon, M. P., Lonigan, C. J., Finch, A. J., and Taylor, C. M.: 1994, Children exposed to disaster: I. Epidemiology of PTSD-traumatic symptoms and symptom profiles, J. Am. Acad. Child Psy. 33(1), 80-92.

Shaw, J. A., Applegate, B., and Schorr, C.: 1996.: Twenty-one-month follow-up study of school-age children exposed to Hurricane Andrew, J. Am. Acad. Child Psy. 35(3), 359-364.

Soong, W. T., Lee, Y. C., Huang, R. R., Liu, Y. S., Yu, W. C., and Chen, Y. S.: 2000, A comparative study of post-traumatic symptoms between students living at Yu-Chih and relocation to Kaohsiung after the Taiwan 921 Earthquake. In: C. H. Loh and I. W. Liao (eds.), Proceedings of International Workshop on Annual Commemoration of Taiwan 921 Earthquake, Vol. IV-Social Aspect, National Center for Research on Earthquake Engineering, Taipei, pp. 308-317.

Wu, Y.C., Hung, F. C., and Chen, S. H.: 2002, "Changes or Not" is the question: the meaning of posttraumatic stress reactions one year after the Taiwan Chi-Chi Earthquake, J. Chin. Inst. Eng. 25(8), 611-620. 